\title{
Filtered Velocity Feedback 제어기를 이용한 평판 능동진동제어 Active Vibration Control of Plates Using Filtered Velocity Feedback Controllers
}

\author{
신 창 주*.홍 진 숙 †.정 의 봉** \\ Changjoo Shin, Chinsuk Hong and Weuibong Jeong \\ (2011년 7월 11일 접수 ; 2011년 8월 30일 심사완료)
}

Key Words : Active Vibration Control(능동진동제어), FVF(filtered velocity feedback), Open Loop Transfer Function(개루프 전달함수)

\begin{abstract}
This paper reports a filtered velocity feedback(FVF) controller, which is an alternative to direct velocity feedback(DVFB) controller. The instability problems at high frequencies due to non-collocated sensor/actuator configuration with the DVFB can be alleviated by the proposed FVF controller. The FVF controller is designed to filter out the unstable high frequency response. The dynamics of a clamped plate under forces and moments and the FVF controllers are formulated. The stability of the control system and performance are investigated with the open loop transfer function(OLTF). It is found that the FVF controller has a higher gain margin than the corresponding DVFB controller owing to the rapid roll-off behavior at high frequencies. Although the gain margin cannot be fully utilized because of the enhancement at the high frequencies, the vibration at the modes lower than the tuning frequency is well controlled. This performance of the FVF controller is shown to be improved from that of the DVFB controller. It is, however, noted that the stability around the tuning frequency is very sensitive so that the enhancement in vibration level should be followed. The reduction performance at low frequencies using the FVF controller should be compromised with the enhancement in the vibration at high frequencies while designing the controller.
\end{abstract}

\section{1. 서 론}

자동차, 비행기 및 선박 등의 수송기계들은 승객 들이 머무는 객실을 보유하고 있다. 수많은 기계들 의 조합으로 이루어진 수송기계들은 목적지까지 오

† 교신저자; 정회원, 울산과학대학 디지탈기계학부

E-mail : cshong@uc.ac.kr

Tel : (052)279-3134, Fax : (052)279-3137

* 정회원, 부산대학교 대학원 기계공학부

** 정회원, 부산대학교 기계공학부

\# 이 논문의 일부는 2011년도 춘계 소음진동 학술대회에서 발표되었음.
가기 위하여 복잡한 기계들이 유기적으로 복합되어 작동한다. 이때 필연적으로 진동과 소음이 발생하게 되며, 이것들은 승객들이 불편을 호소할 수 있는 매 우 큰 요인 중의 하나이다(1). 따라서 고부가가치의 서비스를 제공하는 수송기계들을 개발하기 위해서 는 진동과 소음을 저감해야만 한다.

진동과 소음의 전달 경로는 크게 구조적인 경로 및 공기를 통한 경로로 나눌 수 있다. 그러나 인체에 불편함을 느끼게 하는 진동과 소음은 주로 구조적인 경로를 통해 전달된다 ${ }^{(2)}$. 따라서 인체에 불편함을 야 기하는 진동과 소음을 저감하기 위해서는 구조물의 진동 크기를 줄이는 것이 효과적이다. 구조물의 진동 
저감을 위해 사용하는 전통적인 방법은 구조물 재설 계 또는 수동적인 감쇠를 주는 것이다 ${ }^{(3)}$. 구조물 재 설계는 많은 비용이 수반되고, 수동적으로 감쇠를 주 는 것은 고주파 진동에 대해서 효과적이지만 저주 파 대역의 진동 저감에는 효율성이 현저하게 떨어 진다. 이것에 대한 대안으로써 능동진동제어(active vibration control : $\mathrm{AVC}$ )가 있다. $\mathrm{AVC}$ 는 저주파 대 역에서 높은 성능의 진동 저감을 수행할 수 있다 ${ }^{(4)}$.

$\mathrm{AVC}$ 를 위해 사용되는 대표적인 제어기법은 직접 속도 되먹임 제어(direct velocity feedback : DVFB), 양변위 되먹임 제어(positive position feedback : PPF) 및 가속도 되먹임 제어(acceleration feedback : $\mathrm{AF}$ ) 등이 있다(5). DVFB는 스카이훅(skyhook) 감쇠를 이 용하여 넓은 주파수 대역에서 구조물의 진동을 저감 시킨다. 이것은 단순한 비례제어기를 사용하기 때문 에 제작비용이 매우 낮다. 하지만 $\mathrm{PZT}$ 를 이용하는 $\mathrm{DVFB}$ 의 경우 제어기의 성능을 항상 보장할 수는 없 다. 그 이유는 모멘트 쌍을 이용하는 PZT의 제어력 의 인가 위치와 센서의 위치가 일치하지 않기 때문 이다. Cannon ${ }^{(6)}$ 과 Zhang ${ }^{(7)}$ 은 센서와 액추에이터가 동 일한 위치에 있지 않을 경우 시스템은 물리적으로 한계를 가지게 되며 이것이 제어시스템의 안정성에 영향을 끼친다고 하였다. Getti ${ }^{(8)}$ 는 PZT 액추에이터 를 사용하여 단순 지지보를 능동제어할 경우 발생하 는 DVFB의 한계에 대하여 연구하였다. 그는 센서의 위치와 액추에이터가 생성하는 제어력의 위치가 서 로 다르기 때문에 제어시스템은 조건적인 안정성을 가지게 된다고 주장하였다. DVFB 제어기의 설계변 수는 제어게인 하나뿐이기 때문에 수학적으로 모델 링하기 힘든 복잡한 구조물의 안정성을 확보하며 제 어하는 것이 매우 어렵다.

또 다른 능동제어기법으로 $\mathrm{PPF}$ 가 있다. $\mathrm{PPF}$ 는 Fanson과 Caughy ${ }^{(9)}$ 가 제안하였으며 2차 필터 특성 을 지닌 제어기이다. PPF는 모달변위를 기반으로 제어기로써 특정 모드로 진동하는 구조물을 효과적 으로 제어할 수 있다. $\mathrm{Kwak}^{(10)}$ 은 PPF 제어기의 안 정성과 성능 및 설계법에 대하여 고찰하였다. 그리 고 거대 격자 구조물에 $\mathrm{MIMO} \mathrm{PPF}$ 제어기를 적용 하여 이론 및 실험적으로 구조물의 진동을 저감하 였다 ${ }^{(11)}$. PPF는 하나의 특정모드를 목표로 하여 진 동저감을 수행하는 제어기이기 때문에 다중모드 제 어 시 여러 개의 제어기가 필요하다.
또한, $\mathrm{PPF}$ 와 유사한 가속도 되먹임 제어(acceleration feedback : $\mathrm{AF}$ )가 있다. Juang ${ }^{(12)}$ 은 $\mathrm{AF}$ 를 이 용한 2차 필터를 제안하였다. Kotnic ${ }^{(13)}$ 은 $\mathrm{AF}$ 를 사 용하여 외팔보와 비슷한 특성을 지니는 유연한 로 봇 팔의 끝단을 제어하였다. Preumont ${ }^{(14)}$ 는 보 구조 물에 collocated된 센서와 모멘트 쌍에 $\mathrm{AF}$ 를 적용 하여 $\mathrm{AF}$ 의 특성을 알아보고 단일 주파수에 대한 이론과 실험으로써 진동을 저감하였다. $\operatorname{Shin}^{(15)}$ 은 $\mathrm{AF}$ 등과 같은 2 차 필터의 설계 변수가 제어시스템 이 미치는 영향을 조사하였다. 제어기에 적용되는 게인 및 감쇠비가 제어시스템에 미치는 영향과 2차 필터가 가지는 저역통과 필터의 특성과 유사한 특 성을 확인하였다. 하지만 $\mathrm{AF}$ 역시 $\mathrm{PPF}$ 와 마찬가지 로 하나의 특정모드를 목표로 제어기를 설계하기 때문에 다중모드 제어 시 여러 개의 제어기가 필요 하다.

최근 $\operatorname{Shin}^{(16)}$ 은 모달제어에 기반한 filtered velocity feedback(FVF) 제어기법을 제시하였다. FVF 제어 기의 입력신호로 사용되는 모달속도를 획득하기 위 하여 센서로부터 측정된 신호에 pseudo inverse를 적 용하였다. 그는 FVF를 고차모드에 튜닝하면 DVFB 의 특징인 스카이훅 감쇠 효과를 가져와 다중모드 를 제어할 수 있으며 그와 동시에 2차 필터의 특징 인 roll-off 특성이 나타나 고주파 모드에서 발생할 수 있는 제어시스템의 불안정성을 극복할 수 있다 고 하였다. 그는 양단지지보에 FVF 기법을 적용하 여 단일 제어기로 다중모드 제어를 성공적으로 수 행하였다.

이 논문은 4면이 고정된 평판에 $\mathrm{FVF}$ 기법을 이 용하여 single-input single-output(SISO)로써 다중모 드 제어에 관하여 연구한다. 2절에서는 하중 및 PZT 액추에이터가 제공하는 모멘트가 발생시 4면 이 고정된 균일 평판의 거동을 수학적 모델을 통하 여 설명하였다. 3절에서는 FVF 제어기를 수학적으 로 표현하였으며, 4절에서는 평판에 $\mathrm{FVF}$ 제어기를 적용하여 제어시스템의 안정성 및 성능 평가를 수 행하였다. 그리고 5 절에서 결론을 정리하였다.

\section{2. 평판의 운동지배방정식}

집중하중과 모멘트쌍이 동시에 입력되는 4면이 고정된 균일 평판은 Fig. 1과 같이 표현할 수 있다. 


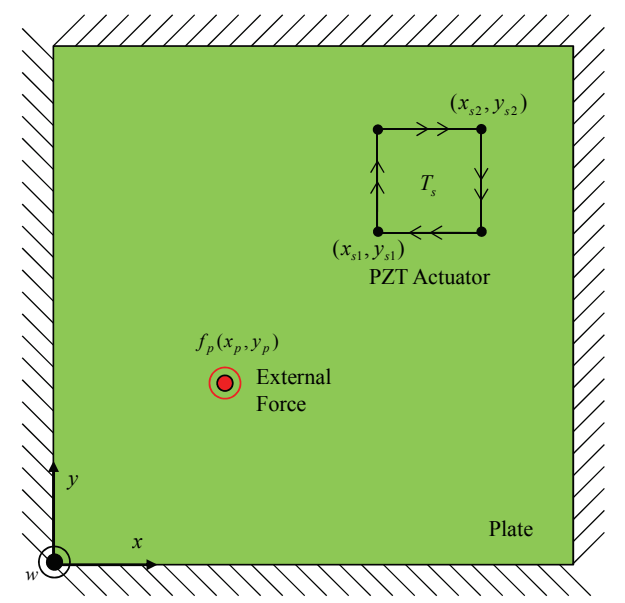

Fig. 1 A clamped plate subjected to a external force and a moment pair

$f_{p}$ 는 외력, 그리고 $T_{s}$ 는 $\mathrm{PZT}$ 액추에이터에 의해 발생되는 제어 모멘트 크기이다. 얇은 평판의 운동 방정식은 식 (1)과 같이 나타낼 수 있다 ${ }^{(17)}$.

$$
\begin{aligned}
D\left(\frac{\partial^{4} w}{\partial x^{4}}\right. & \left.+2 \frac{\partial^{4} w}{\partial x^{2} \partial y^{2}}+\frac{\partial^{4} w}{\partial y^{4}}\right)+\rho h \frac{\partial^{2} w}{\partial t^{2}} \\
& =f_{p}(x, y, t)+\left(-\frac{\partial T_{x}}{\partial x}-\frac{\partial T_{y}}{\partial y}\right)
\end{aligned}
$$

여기서 $D$ 는 평판의 굽힘강성이며 식(2)와 같이 나 타낼 수 있다.

$$
D=\frac{E h^{3}}{12\left(1-\nu^{2}\right)},
$$

여기서 $E$ 는 Young률, $h$ 는 평판의 두께, 그리고 $\nu$ 는 푸아송비이다. 그리고 $\rho$ 는 밀도, $f_{p}(x, y, t)$ 는 외 력, $T_{x}$ 는 $\mathrm{PZT}$ 액추에이터에서 $x$ 축을 따라 발생하 는 모멘트 크기이며, $T_{y}$ 는 $\mathrm{PZT}$ 액추에이터에서 $y$ 축을 따라 발생하는 모멘트 크기이다. 평판의 변위 응답을 조화운동으로 가정하면 식 (3)과 같다.

$$
w(x, y, t)=\sum_{m=1}^{\infty} \sum_{n=1}^{\infty} p_{m n}(\omega) \Theta_{m n}(x, y) e^{j \omega t},
$$

여기서 $m$ 은 $x$ 축 방향에 대한 모드첨자, $n$ 은 $y$ 축 방향에 대한 모드첨자, $p_{m n}$ 은 모달변위, 그리고 $\Theta_{m n}$ 은 모드형상이다. 평판의 거동을 자유진동으로 가정하고 $\left(f_{p}=T_{x}=T_{y}=0\right)$ 식 (3)을 식 (1)에 대입
후, 모드형상 $\Theta_{u v}$ 를 양변에 곱하고 평판 전체 면적 에 대하여 적분하면 식 (4)와 같다.

$$
\begin{aligned}
D \int_{0}^{L_{y}} \int_{0}^{L_{x}} \sum_{m=1 n=1}^{\infty} \sum_{m n}^{\infty} p_{m n} \times \\
\\
\quad\left(\frac{\partial^{4} \Theta_{m n}}{\partial x^{4}}+2 \frac{\partial^{4} \Theta_{m n}}{\partial x^{2} \partial y^{2}}+\frac{\partial^{4} \Theta_{m n}}{\partial y^{4}}\right) \Theta_{u v} d x d y \\
\quad=\rho h \omega_{m n}^{2} \int_{0}^{L_{y}} \int_{0}^{L_{x}} \sum_{m=1}^{\infty} \sum_{n=1}^{\infty} p_{m n} \Theta_{m n} \Theta_{u v} d x d y
\end{aligned}
$$

여기서 $L_{x}, L_{y}$ 는 평판의 $x$ 축과 $y$ 축 방향의 길이이 며 $\omega_{m n}$ 은 $\Theta_{m n}$ 에 각기 해당하는 구조물의 고유진동 수이다. 모드직교성에 이용하면 다음과 같은 결과를 얻을 수 있다.

$$
\begin{aligned}
\int_{0}^{L_{y}} \int_{0}^{L_{x}} \sum_{m=1 n=1}^{\infty} \sum_{m n}^{\infty} p_{m n} \Theta_{u v} d x d y \\
=\left\{\begin{array}{cc}
p_{m n} L_{x} L_{y} \text { for } m, n=u, v \\
0 & \text { for } m, n \neq u, v
\end{array}\right.
\end{aligned}
$$

따라서 식 (4)는 다음과 같이 나타낼 수 있다.

$$
\begin{aligned}
& D \int_{0}^{L_{y}} \int_{0}^{L_{x}} \sum_{m=1}^{\infty} \sum_{n=1}^{\infty} p_{m n} \times \\
& \left(\frac{\partial^{4} \Theta_{m n}}{\partial x^{4}}+2 \frac{\partial^{4} \Theta_{m n}}{\partial x^{2} \partial y^{2}}+\frac{\partial^{4} \Theta_{m n}}{\partial y^{4}}\right) \Theta_{u v} d x d y \\
& =\left\{\begin{array}{cc}
\rho h L_{x} L_{y} \omega_{m n}^{2} p_{m n} & \text { for } m, m=u, v \\
0 & \text { for } m, n \neq u, v
\end{array}\right.
\end{aligned}
$$

식 (6)을 이용하여 고유치 문제를 행렬형식으로 표현하면

$$
\left[\mathrm{K}-\omega^{2} \mathrm{M}\right]_{\mathrm{p}}=0,
$$

여기서

$$
\begin{aligned}
& \mathrm{K}=\rho h L_{x} L_{y} \operatorname{diag}\left(\omega_{m n}^{2}\right), \\
& \mathrm{M}=\rho h L_{x} L_{y} \mathrm{I},
\end{aligned}
$$

그리고 모달변위 벡터는 다음과 같다.

$$
\mathrm{p}=\left[p_{11} p_{21} p_{31} \cdots p_{12} p_{22} p_{32} \cdots p_{1 k} p_{2 k} p_{3 k} \cdots p_{m n}\right]^{T}
$$

구조물의 고유진동수를 대각행렬로 나타내면 식 (11)과 같다. 


$$
\operatorname{diag}\left(\omega_{m n}^{2}\right)=\left[\begin{array}{ccccccccc}
\omega_{11}^{2} & 0 & 0 & \cdots & 0 & 0 & 0 & \cdots & 0 \\
0 & \omega_{21}^{2} & 0 & \cdots & 0 & 0 & 0 & \cdots & 0 \\
0 & 0 & \omega_{31}^{2} & \cdots & 0 & 0 & 0 & \cdots & 0 \\
\vdots & \vdots & \vdots & \ddots & \vdots & \vdots & \vdots & \ddots & \vdots \\
0 & 0 & 0 & \cdots & \omega_{1 k}^{2} & 0 & 0 & \cdots & 0 \\
0 & 0 & 0 & \cdots & 0 & \omega_{2 k}^{2} & 0 & \cdots & 0 \\
0 & 0 & 0 & \cdots & 0 & 0 & \omega_{3 k}^{2} & \cdots & 0 \\
\vdots & \vdots & \vdots & \ddots & \vdots & \vdots & \vdots & \ddots & \vdots \\
0 & 0 & 0 & \cdots & 0 & 0 & 0 & \cdots & \omega_{m n}^{2}
\end{array}\right]
$$

Warburton $^{(18)}$ 은 보 함수의 특성을 이용하여 평판 의 모드형상과 고유진동수를 제시하였다. 그가 제시 한 평판의 모드형상 $\Theta_{m n}$ 은 다음과 같다.

$$
\Theta_{m n}(x, y)=\phi_{m}(x) \psi_{n}(y)
$$

여기서 $\phi_{m}(x)$ 와 $\psi_{n}(y)$ 는 평판의 각 $x$ 축과 $y$ 축을 따라 나타나는 양단이 고정된 보의 $m$ 차 및 $n$ 차 모드 형상이며 식(13)을 이용하여 양단지지 보의 모드 형상을 구할 수 있다.

$$
\left\{\begin{array}{c}
\phi(x)=\cos \gamma\left(\frac{x}{L_{x}}-\frac{1}{2}\right) \\
+k \cosh \gamma\left(\frac{x}{L_{x}}-\frac{1}{2}\right) \text { for } m=2,4,6, \cdots \\
\text { where } k=\frac{\sin \frac{\gamma}{2}}{\sinh \frac{\gamma}{2}}, \\
\text { and } \tan \frac{\gamma}{2}+\tanh \frac{\gamma}{2}=0, \\
\phi(x)=\sin \gamma^{\prime}\left(\frac{x}{L_{x}}-\frac{1}{2}\right) \\
+k^{\prime} \sinh \gamma^{\prime}\left(\frac{x}{L_{x}}-\frac{1}{2}\right) \text { for } m=3,5,7, \cdots \\
\text { where } k^{\prime}=-\frac{\sin \frac{\gamma^{\prime}}{2}}{\sinh \frac{\gamma^{\prime}}{2}}, \\
\text { and } \tan \frac{\gamma^{\prime}}{2}-\tanh \frac{\gamma^{\prime}}{2}=0
\end{array},\right.
$$

그리고 고유진동수는 식 (14)와 같다.

$$
f_{m n}=\frac{\lambda_{m n} h \pi}{L_{x}} \sqrt{\frac{E}{48 \rho\left(1-\nu^{2}\right)}},
$$

Table 1 Coefficients for $\lambda_{m n}$

\begin{tabular}{c|c|c}
\hline \hline$m, n$ & 2 & $3,4,5, \cdots$ \\
\hline$G_{x}, G_{y}$ & 1.506 & $m-\frac{1}{2}$ \\
\hline$H_{x}, H_{y}$ & 1.248 & $\left(m-\frac{1}{2}\right)^{2}\left[1-\frac{2}{\left(m-\frac{1}{2}\right)}\right]$ \\
\hline$J_{x}, J_{y}$ & 1.248 & $\left(m-\frac{1}{2}\right)^{2}\left[1-\frac{2}{\left(m-\frac{1}{2}\right)}\right]$ \\
\hline
\end{tabular}

여기서 $\lambda_{m n}$ 은 식 (15)와 같다.

$$
\begin{aligned}
\lambda_{m n}^{2}= & G_{x}^{4}+G_{y}^{4}\left(\frac{L_{y}}{L_{x}}\right)^{4} \\
& +2\left(\frac{L_{y}}{L_{x}}\right)^{2}\left[\nu H_{x} H_{y}+(1-\nu) J_{x} J_{y}\right]
\end{aligned},
$$

식 (15)에서 4면이 고정된 평판에 적용된 $G_{x}$, $G_{y}, H_{x}, H_{y}, J_{x}$ 및 $J_{y}$ 는 Table 1 과 같다. 강제진동 응답을 계산하기 위하여 외력이 한 점 $\left(x_{p}, y_{p}\right)$ 에 작 용한다면 식 (16)과 같이 나타낼 수 있다.

$$
f_{p}(x, y, t)=F_{p}(\omega) \delta\left(x-x_{p}, y-y_{p}\right) e^{j \omega t},
$$

여기서 $F_{p}$ 는 외력의 크기이고 $\delta$ 는 Dirac delta함수이 다. 그리고 Fig. 1에서 보인 PZT 액추에이터가 모멘 트 크기 $T_{s}$ 로 작용한다면 PZT 액추에이터에 의한 가 진력은 식 (17), 그리고 (18)과 같이 나타낼 수 있다.

$$
\begin{aligned}
& T_{x}(x, y, t) \\
& =\left[\begin{array}{c}
T_{s} \delta\left(x-x_{s 2}\right)\left\{U\left(y-y_{s 1}\right)-U\left(y-y_{s 2}\right)\right\} \\
-T_{s} \delta\left(x-x_{s 1}\right)\left\{U\left(y-y_{s 1}\right)-U\left(y-y_{s 2}\right)\right\}
\end{array}\right] e^{j \omega t},
\end{aligned}
$$

$$
\begin{aligned}
& T_{y}(x, y, t) \\
& =\left[\begin{array}{c}
T_{s} \delta\left(y-y_{s 1}\right)\left\{U\left(x-x_{s 1}\right)-U\left(x-x_{s 2}\right)\right\} \\
-T_{s} \delta\left(y-y_{s 2}\right)\left\{U\left(x-x_{s 1}\right)-U\left(x-x_{s 2}\right)\right\}
\end{array}\right] e^{j \omega t},
\end{aligned}
$$

여기서 $U$ 는 $\operatorname{step}$ 함수이고, $x_{s 1}, x_{s 2}, y_{s 1}$ 및 $y_{s 2}$ 는 PZT 액추에이터의 가장자리를 나타내는 좌표이다. 식 (3)을 식(1)에 대입 후 모드형상 $\Theta_{u v}$ 를 양변에 곱한다. 그리고 평판 전체 면적에 대하여 적분하면 식 (19)와 같다. 그리고 식 (19)의 우변에 존재하는 외력항과 모멘트항은 이중적분을 통해 식 (20) 그리 고 식 (21)과 같이 각각 표현할 수 있다. 


$$
\begin{aligned}
& D \int_{0}^{L_{y}} \int_{0}^{L_{x}} \sum_{m=1 n=1}^{\infty} \sum_{m n}^{\infty} p_{m} \times\left(\frac{\partial^{4} \Theta_{m n}}{\partial x^{4}}+2 \frac{\partial^{4} \Theta_{m n}}{\partial x^{2} \partial y^{2}}+\frac{\partial^{4} \Theta_{m n}}{\partial y^{4}}\right) \Theta_{u v} d x d y-\rho h \omega_{m n}^{2} \int_{0}^{L_{y}} \int_{0}^{L_{x}} \sum_{m=1 n=1}^{\infty} \sum_{m n}^{\infty} p_{m n} \Theta_{u v} d x d y \\
& =\int_{0}^{L_{y}} \int_{0}^{L_{x}} F_{p} \delta\left(x-x_{p}, y-y_{p}\right) \Theta_{u v} d x d y+\left(-\int_{0}^{L_{y}} \int_{0}^{L_{x}} \frac{\partial T_{x}}{\partial x} \Theta_{u v} d x d y-\int_{0}^{L_{y}} \int_{0}^{L_{x}} \frac{\partial T_{y}}{\partial y} \Theta_{u v} d x d y\right) \\
& u, v=1,2,3, \cdots
\end{aligned}
$$$$
F_{u v}=\int_{0}^{L_{y}} \int_{0}^{L_{x}} F_{p}(x, y) \Theta_{u v}(x, y) d x d y,
$$$$
T_{u v}=T_{s}\left\{\frac{\partial \psi_{v}\left(y_{s 1}\right)}{\partial y}-\frac{\partial \psi_{v}\left(y_{s 2}\right)}{\partial y}\right\} \int_{x_{s 1}}^{x_{s 2}} \phi_{u}(x) d x
$$$$
+T_{s}\left\{\frac{\partial \phi_{u}\left(x_{s 1}\right)}{\partial x}-\frac{\partial \phi_{u}\left(x_{s 2}\right)}{\partial x}\right\} \int_{y_{s 1}}^{y_{s 2}} \psi_{v}(y) d y .
$$$$
\equiv T_{s} \check{\Theta}\left(x_{s}, y_{s}\right)
$$

그리고 평판의 속도거동은 식 (26)과 같다.

$$
V\left(x_{s}, y_{s}\right)=j \omega W\left(x_{s}, y_{s}\right)
$$

구조물의 총운동에너지(total kinetic energy; TKE)

식 (19)를 $x$ 축 방향에 대하여 $M$ 개, $y$ 축 방향에 대하여 $N$ 개의 유한모드중첩을 통해 행렬식으로 식 (22)와 같이 나타낼 수 있다.

$$
\left[-\omega^{2} \mathrm{M}+j \omega \mathrm{D}+\mathrm{K}\right] \mathrm{p}=\mathrm{F}
$$

여기서 평판의 감쇠를 점성감쇠로 가정하면

$$
\mathrm{D}=\rho h L_{x} L_{y} \operatorname{diag}\left(2 \zeta_{m n} \omega_{m n}\right),
$$

여기서 $\zeta_{m n}$ 은 감쇠비이며, $\mathrm{F}=F_{u v}+T_{u v}$ 이다. 따라 서 $\left(x_{s}, y_{s}\right)$ 위치에서의 평판의 변위거동은 식 (24) 와 같이 나타낼 수 있다.

$$
W\left(x_{s}, y_{s}\right)=\Theta\left(x_{s}, y_{s}\right)\left[-\omega^{2} \mathrm{M}+j \omega \mathrm{D}+\mathrm{K}\right]^{-1} \mathrm{~F},
$$

여기서 $\Theta\left(x_{s}, y_{s}\right)$ 는 다음과 같이 정의한 모달벡터에 의해 구할 수 있다.

$$
\Theta(x, y)=\left\{\begin{array}{c}
\Theta_{11}(x, y) \\
\Theta_{21}(x, y) \\
\Theta_{31}(x, y) \\
\vdots \\
\Theta_{12}(x, y) \\
\Theta_{22}(x, y) \\
\Theta_{32}(x, y) \\
\vdots \\
\Theta_{1 k}(x, y) \\
\Theta_{2 k}(x, y) \\
\Theta_{3 k}(x, y) \\
\vdots \\
\Theta_{M N}(x, y)
\end{array}\right\}=\left\{\begin{array}{c}
\phi_{1}(x) \psi_{1}(y) \\
\phi_{2}(x) \psi_{1}(y) \\
\phi_{3}(x) \psi_{1}(y) \\
\vdots \\
\phi_{1}(x) \psi_{2}(y) \\
\phi_{2}(x) \psi_{2}(y) \\
\phi_{3}(x) \psi_{2}(y) \\
\vdots \\
\phi_{1}(x) \psi_{k}(y) \\
\phi_{2}(x) \psi_{k}(y) \\
\phi_{3}(x) \psi_{k}(y) \\
\vdots \\
\phi_{M}(x) \psi_{N}(y)
\end{array}\right\},
$$

\section{Filtered Velocity Feedback Control}

$\operatorname{Shin}^{(16)}$ 은 모달 제어를 기반한 filtered velocity feedback(FVF) 기법을 제안하여 단일 제어기로 양단지지보의 다중모드 진동을 제어하였다. 하지 만 2차 필터인 $\mathrm{FVF}$ 제어기가 구조물의 하나의 특정 고유진동수에 튜닝되어 있다면 모달제어와 유사한 특성을 나타낼 수 있다. 센서에서 측정되 는 신호는 수학적으로 모달속도와 모드형상함수 가 곱의 중첩으로써 표현된다. 여기서 구조물 위 에 센서가 놓여있는 위치와 제어하려는 모드가 결정되면 모드형상 함수는 하나의 실수로 표현된 다. 따라서 구조물의 응답을 계산할 때 적용되는 모드형상함수는 제어기 응답 특성에서 그 크기에 는 영향을 주지만 위상과는 무관하다. 또한 이것 은 실수로 표현되는 상수이기 때문에 제어기의 게인에 포함시킬 수 있다. 따라서 물리좌표계 상 에 놓여있는 센서에서 측정된 신호를 구조물의 특정 고유진동수에 튜닝된 제어기에 직접 입력시 키더라도 모달 제어를 기반으로 하는 $\mathrm{FVF}$ 제어 기와 같은 효과를 나타낼 수 있게 된다. 따라서 
Shin이 제안한 FVF 제어기를 식 (29)와 같이 다시 표현할 수 있다.

$$
\ddot{q}+2 \zeta_{c} \omega_{c} \dot{q}+\omega_{c}^{2} q=-g \omega_{c}^{2} V
$$

여기서 $q$ 는 제어기의 변위, $\zeta_{c}$ 는 제어기의 감쇠비, $\omega_{c}$ 는 제어기의 튜닝주파수, $g$ 는 제어게인, 그리고 $V$ 는 구조물에 부착된 속도센서 신호이다. FVF 제 어기가 적용된 시스템의 블록다이어그램은 Fig. 2와 같다. $\mathrm{p}_{\mathrm{p}}$ 는 외란에 의해 구조물에서 발생한 모달변 위이다. $\mathrm{G}$ 는 플랜트이며 구조물에 부착된 $\mathrm{PZT}$ actuator에 단위 전압이 인가될 때 센서에서 측정된 구조물의 속도응답을 의미한다.

$$
\mathrm{G}(\omega)=j \omega \Theta\left(x_{s}, y_{s}\right)\left[-\omega^{2} \mathrm{M}+j \omega \mathrm{D}+\mathrm{K}\right]^{-1} \check{\Theta}\left(x_{s}, y_{s}\right)
$$

외란에 의해 구조물의 거동은 $\left(x_{s}, y_{s}\right)$ 에 놓여있는 속도센서로부터 $V_{p}$ 신호가 획득되며 $\mathrm{H}_{\mathrm{FVF}}$ 로 입력 된다. FVF 제어기는 제어기의 전달함수 $H(\omega)$ 와 $g$ 에 의해 제어신호 $T_{s}$ 를 생성한다. 여기서 $H(\omega)$ 와 $\mathrm{H}_{\mathrm{FVF}}$ 는 다음과 같다.

$$
\begin{aligned}
& H(\omega)=\frac{\omega_{c}^{2}}{\omega_{c}^{2}-\omega^{2}+j 2 \zeta_{c} \omega_{c} \omega} \\
& \mathrm{H}_{\mathrm{FVF}}(\omega)=-g H(\omega)
\end{aligned}
$$

$T_{s}$ 에 의해 구조물에 부착된 $\mathrm{PZT}$ 액추에이터가 작동하며, 그로인해 속도센서로부터 $V_{s}$ 를 획득하게 된다. 최종적으로 속도센서로부터 획득되는 제어된 구조물의 거동은 $V_{r}$ 이 된다. 따라서 $V_{r}$ 은 다음과 같이 나타낼 수 있다.

$$
\begin{aligned}
& \begin{aligned}
V_{r}(\omega) & =V_{p}(\omega)+V_{s}(\omega) \\
& =V_{p}(\omega)+\mathrm{G}(\omega) T_{s}(\omega)
\end{aligned} \\
& T_{s}(\omega) \text { 는 } \mathrm{H}_{\mathrm{FVF}} \text { 와 } V_{r} \text { 에 의해 생성되므로 } \\
& T_{s}=\mathrm{H}_{\mathrm{FVF}} V_{r} .
\end{aligned}
$$

따라서 센서 위치에서 관찰되는 제어된 구조물의 최 종 전압 인 $V_{r}$ 및 제어 신호인 $T_{s}$ 는 다음과 같다.

$$
\begin{aligned}
& V_{r}=\left[\mathrm{I}-\mathrm{GH}_{\mathrm{FVF}}\right]^{-1} V_{p} \\
& T_{s}=\mathrm{H}_{\mathrm{FVF}}\left[\mathrm{I}-\mathrm{GH}_{\mathrm{FVF}}\right]^{-1} V_{p}
\end{aligned}
$$

그리고 제어기의 특성변화를 관찰할 수 있는 개루 프전달함수(open loop transfer function; OLTF)는 식 (37)과 같다.

$$
\operatorname{OLTF}(\omega)=-\mathrm{GH}_{\mathrm{FVF}}
$$

식 (37)은 Nyquist 안정성 판별법을 적용하기 위 하여 음수 되먹임 제어(negative feedback control) 의 표준 관계식과 비교하여 표현한 것이다.

\section{FVF 제어기 설계 및 성능 평가}

$\operatorname{Shin}^{(16)}$ 은 제어시스템의 안정성 개선을 위하여 $\mathrm{FVF}$ 를 제안하였으며 보 구조물에 대하여 적용하여 원리, 설계방법 그리고 유용성을 설명하였다. $\mathrm{FVF}$ 제어기의 설계변수는 식 (29)에서 보인 바와 같이 제어기의 튜닝주파수, 감쇠비 및 게인이다. 제어기 의 튜닝주파수는 FVF 제어기의 차단주파수를 결정 한다. FVF 제어기는 튜닝주파수를 중심으로 저주파

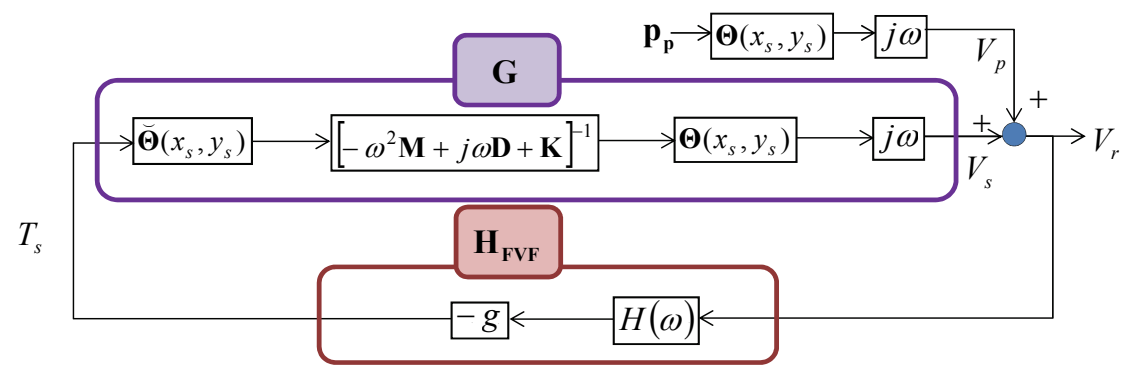

Fig. 2 Block diagram for active feedback control using FVF controller 
대역에는 능동감쇠력을 발생시키는 신호를 통과시 키고, 고주파 대역에는 시스템의 불안정하게 하는 성분을 차단한다. 따라서 FVF 제어기의 튜닝주파수 를 관심주파수 대역 내의 고차모드에 튜닝하면 그 이하에 존재하는 구조물의 응답을 제어할 수 있게 된다. 이 연구에서는 FVF 제어기의 튜닝주파수를 선정하기 위하여 $2 \mathrm{kHz}$ 를 기준으로 인근의 최저 피 크 레벨을 같는 구조물의 고유진동수 $(2150 \mathrm{~Hz})$ 로 선정하였다. 이것은 튜닝주파수 근처의 응답들이 일 으키는 불안정성을 최소화시키기 위한 것이다 ${ }^{(16)}$.

두 번째 제어기 설계변수인 제어기의 감쇠비는 제어기의 공진에서 갖는 피크레벨을 약화시키기에 충분한 감쇠비를 선정하였다. 감쇠비가 증가하면 공 진주파수를 중심으로 주위의 위상 특성을 변화시키 므로 위상변화의 허용범위를 고려하여 정해야 한다. 이 연구에서는 제어기의 감쇠비를 0.8 로 정하였다.

세 번째 제어기의 설계변수인 제어게인은 게인마 진을 파악하여 최대게인을 정하게 된다. 제어기의 튜닝주파수를 결정 후 앞서 정한 감쇠비를 적용하 여 OLTF를 계산하여 게인마진을 결정한다. 먼저 $\mathrm{FVF}$ 제어기의 튜닝주파수를 결정하기 위하여 플랜 트 응답을 통하여 PZT 액추에이터가 구조물이 미 치는 영향을 먼저 파악해야 한다.

Fig. 3은 한변의 길이가 $24 \mathrm{~mm}$ 인 정사각형 형태 의 PZT 액추에이터 중심을 $\left(0.3 L_{x}, 0.7 L_{y}\right)$ 에 설치하 였을 때 플랜트 응답이다. 이 플랜트 응답은 DVFB 제어기를 적용한 경우의 개루프 전달함수로 취급하 여 $\mathrm{DVFB}$ 제어의 안정성을 판단할 수 있다. 이 계산 에 적용된 물성치는 Table2와 같다. Fig. 3(a)에 의하 면 플랜트 응답은 주파수가 증가할수록 그 크기가 커지고 있다. 대부분의 위상은 $\pm 90^{\circ}$ 안에 존재하고 있 으나 $17.3 \mathrm{kHz}$ 이상 주파수 대역에 존재하는 플랜트 응답은 $-90^{\circ}$ 를 벗어났다. 이것은 non-collocation 시 스템의 고주파대역에서 발생하는 일반적인 현상으 로 해당 모드의 파장이 $s$ 보다 짧을 때 발생한다. 그리고 이 위상변화 때문에 제어시스템은 불안정성 을 내포하게 된다. Fig. 3(b)의 Nyquist diagram에 의 하면 $17.3 \mathrm{kHz}$ 이하에 존재하는 플랜트 응답은 모두 양의 실수부 존재하기 때문에 안정한 것으로 판단 된다. $17.3 \mathrm{kHz}$ 이상의 주파수 대역에 존재하는 응답 들은 음의 실수부에 나타났다. 음의 실수부에 표현 된 응답들은 게인이 증가함에 따라 제어시스템을
Table 2 Mechanical properties

\begin{tabular}{c|c|c|c}
\hline \hline Parameters & Symbol & Unit & Values \\
\hline Width of the panel & $L_{x}$ & $\mathrm{~m}$ & 0.52 \\
\hline Length of the panel & $L_{y}$ & $\mathrm{~m}$ & 0.42 \\
\hline Thickness of panel & $h$ & $\mathrm{~m}$ & 0.001 \\
\hline Density & $\rho$ & $\mathrm{kg} / \mathrm{m}^{3}$ & 2950 \\
\hline Length of the PZT patch & $s$ & $\mathrm{~m}$ & 0.024 \\
\hline Young's modulus & $E$ & $\mathrm{GPa}$ & 60 \\
\hline Poisson's ratio & $\nu$ & & 0.3 \\
\hline Damping ratio & $\zeta$ & & 0.012
\end{tabular}
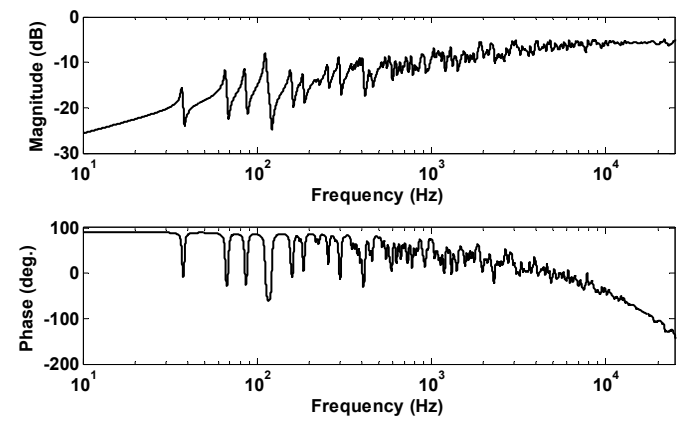

(a) Bode diagram

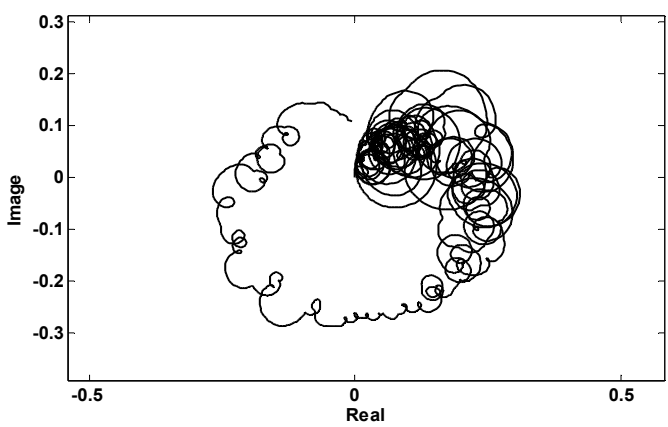

(b) Nyquist diagram

Fig. 3 Calculated plant response up to $27 \mathrm{kHz}$ when the PZT actuator is placed at $\left(0.3 L_{x}, 0.7 L_{y}\right)$

불안정하게 만들 수 있다. 이 고주파 대역 성분으 로 인하여 DVFB 제어기의 게인마진이 약 4정도 로 제한됨을 알 수 있다. 이 연구에서 제시하는 $\mathrm{FVF}$ 제어기는 $17.3 \mathrm{kHz}$ 이상의 고주파 대역에서 보 이는 불안정성의 영향을 감소시키는 역할을 하게 된다.

Fig. 4는 제어게인 1 , 감쇠비 0.8 , 그리고 튜닝주 파수가 $2150 \mathrm{~Hz}$ 로 튜닝된 $\mathrm{FVF}$ 제어기의 전달함수 이다. 

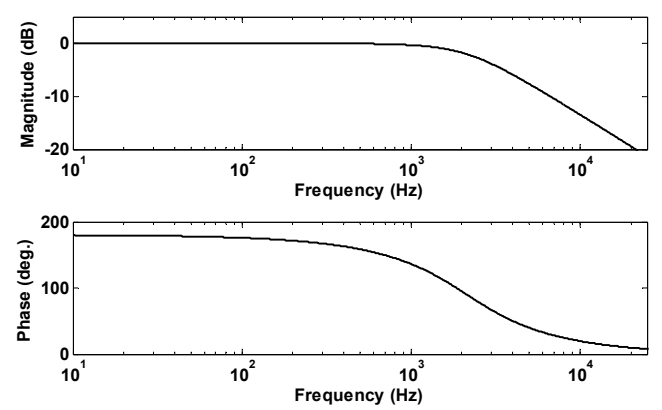

Fig. 4 Transfer function of FVF controller with tuning frequency of $2150 \mathrm{~Hz}$, gain of 1 , and damping ratio of 0.8 up to $27 \mathrm{kHz}$

FVF 제어기는 저역통과필터와 유사하게 튜닝주파 수인 $2150 \mathrm{~Hz}$ 이상의 고주파 대역에서는 roll-off 특성 을 보였다. Roll-off 특성에 의해 Fig. 3에서 보인 고 주파 대역의 불안정한 플랜트 응답의 크기를 줄일 수 있다. 또한 모델링되지 않은 고주파 대역의 응답 크기를 줄임으로써 제어시스템의 안정성을 확보할 수 있게 된다. 그러나 제어기가 설계된 주파수에 인 접하는 고차 모드일 경우, 상대적으로 약하게 나타나 는 roll-off 특성으로 인해 구조물의 응답이 제어 전 대비 다소 증가할 수 있을 것으로 판단된다.

Fig. 5는 FVF 제어기의 튜닝주파수를 $2150 \mathrm{~Hz}$, 감쇠비를 0.8 , 그리고 제어게인을 1 로 설계하였을 때 획득한 OLTF이다. Fig. 5(a)에 의하면 1차 모드 $(37 \mathrm{~Hz})$ 의 응답이 가장 낮게 나타났다. 따라서 폐루 프제어 시 제어 효과가 가장 약하게 나타날 것으로 판단된다. 반면 4 차 모드 $(112 \mathrm{~Hz})$ 의 경우 그 응답 의 크기가 가장 크게 나타났기 때문에 폐루프제어 시 제어 효과가 두드러지게 나타날 것으로 예측할 수 있다. 또한 FVF 제어기의 roll-off 특성에 의하 여 OLTF의 크기가 줄어들고 있는 것을 확인할 수 있다. 따라서 플랜트 응답을 통해 확인한 고주파 대 역에서 발생할 수 있는 제어시스템의 불안정성을 최소화 시킬 수 있을 것으로 판단된다. OLTF의 위 상은 튜닝주파수 이후로는 $-90^{\circ}$ 를 지나버렸다. 따라 서 FVF 제어시스템이 불안정성을 일부 내포하게 되었다. Fig. 5(b)의 Nyquist 선도에 의하면 감쇠비 에 의해 튜닝주파수보다 높은 인근 모드의 응답들 은 시계방향으로 회전하고 있다. 고차모드의 일부는 Nyquist 선도의 좌반면에 존재하고 있으므로 게인 1 이 적용된 $\mathrm{FVF}$ 제어시스템은 조건부 안정성을
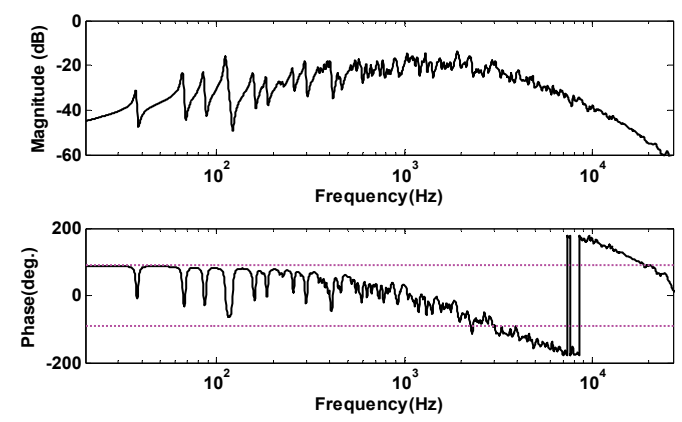

(a) Bode diagram

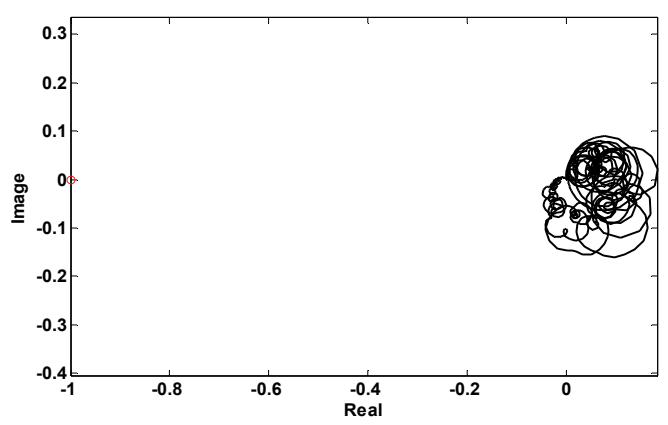

(b) Nyquist diagram

Fig. 5 Calculated open loop transfer function of FVF controller with tuning frequency of $2150 \mathrm{~Hz}$, gain of 1 , and damping ratio of 0.8 up to 27 $\mathrm{kHz}$ when the PZT actuator is placed at $\left(0.3 L_{x}, 0.7 L_{y}\right)$

가지는 것으로 판단할 수 있다. 그리고 Fig. 5(b)에 의해면 게인 마진은 31.64 를 확보할 수 있다. 하지 만 최대 게인 마진에 가깝게 게인의 크기를 증가시 킬수록 Nyquist 선도 좌반면에 존재하는 불안정한 모드의 응답이 $(-1, j 0)$ 에 가까이 다가간다. 그러면 폐루프제어 시 그에 해당하는 구조물의 주파수 응 답이 급격하게 증가하게 된다.

Fig. 6은 FVF 제어기의 튜닝주파수를 $2150 \mathrm{~Hz}$, 감쇠비를 0.8 , 그리고 제어게인을 13.68 로 설계하였 을 때 획득한 OLTF이다. Fig. 6(a)에 의해 게인이 증가함에 따라 OLTF의 크기를 증가시키는 반면 위 상에는 영향을 주지 않는 것을 확인할 수 있다. Fig. 6(b)는 OLTF를 Nyquist 선도로 나타낸 것이다. 고차모드의 일부는 $(-1, j 0)$ 을 중심으로 하는 단위 원 내부에 존재하고 있다. 특히 단위원 내부에 있는 응답일지라도 고주파대역의 응답일수록 제어기의 roll-off 특성으로 인해 그 크기가 급격하게 작아지는 

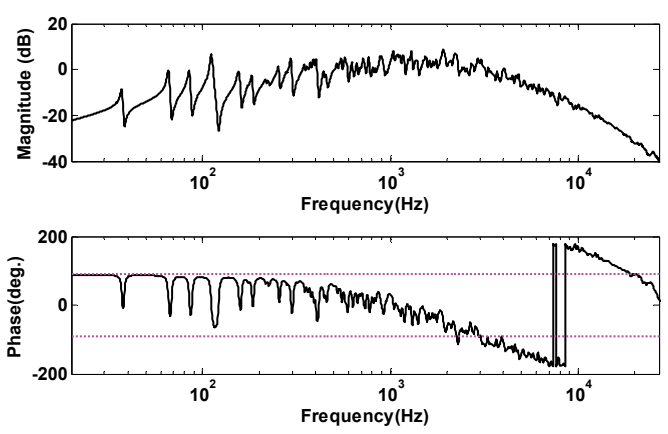

(a) Bode diagram

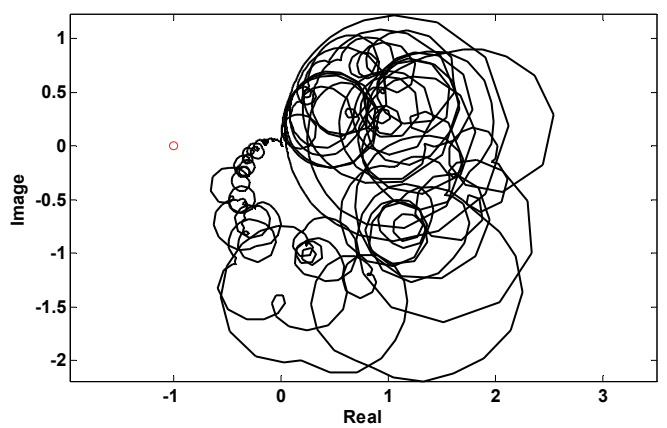

(b) Nyquist diagram

Fig. 6 Calculated open loop transfer function of FVF controller with tuning frequency of $2150 \mathrm{~Hz}$, gain of 13.68, and damping ratio of 0.8 up to $27 \mathrm{kHz}$ when the PZT actuator is placed at $\left(0.3 L_{x}, 0.7 L_{y}\right)$

경향을 보여주고 있다. 따라서 해당 FVF 제어시스 템은 $(-1, j 0)$ 점을 내포하는 OLTF가 존재하지 않 으며 제어시스템은 안정하다고 판정할 수 있다. 그 리고 $(-1, j 0)$ 점을 내포하는 OLTF에 해당되는 주 파수 응답들은 폐루프제어 시 제어 전 대비 제어 후 구조물의 응답이 증가할 것이다. 하지만 OLTF 응답의 대부분은 $(-1, j 0)$ 을 중심으로 하는 단위원 외부에 존재하기 때문에 폐루프 제어 시 구조물의 응답이 줄어들 것이다.

Fig. 7은 평판에 FVF 폐루프 제어시스템을 구성 후 $\left(0.4 L_{x}, 0.5 L_{y}\right)$ 위치에서 단위힘이 입력될 때 $\left(0.3 L_{x}, 0.7 L_{y}\right)$ 위치에서의 속도 응답이다. FVF 제어 기는 $2150 \mathrm{~Hz}$ 에 튜닝되었으며 제어 게인은 13.68 , 그 리고 감쇠비는 0.8 이 적용되었다. Fig. 6 에서 예측한 바와 같이 튜닝모드 이하에 존재하는 다중모드의 제 어가 가능하였다. 평판의 진동은 1 차 모드 응답이

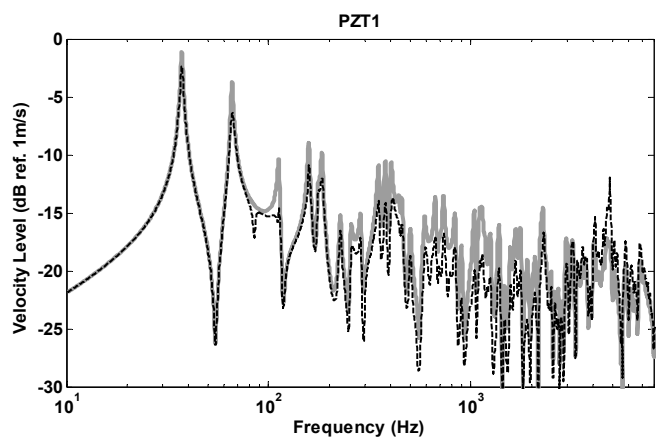

Fig. 7 The closed loop velocity level of the plate at $\left(0.3 L_{x}, 0.7 L_{y}\right)$ with the FVF controller tuned to $2150 \mathrm{~Hz}$ with the gain of 13.68 , and damping ratio of 0.8 , excited by the concentrated unit force at $\left(0.4 L_{x}, 0.5 L_{y}\right)$ - without control (solid line) and with control (dashed line)

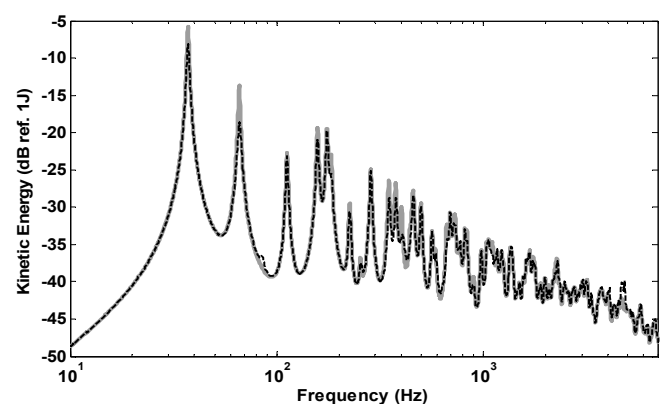

Fig. 8 The total kinetic energy of the plate with the FVF controller tuned to $2150 \mathrm{~Hz}$ with the gain of 13.68, and damping ratio of 0.8 , excited by the concentrated unit force at $\left(0.4 L_{x}, 0.5 L_{y}\right)$ - without control (solid line) and with control (dashed line)

가장 지배적인 나타났지만, 1 차 모드의 플랜트의 성 능이 약하게 나타났기 때문에 제어 전 응답(-1.14 $\mathrm{dB})$ 대비 제어 후 응답 $(-2.38 \mathrm{~dB})$ 이 크게 줄어들지 못하였다. 반면 4차 모드의 경우 제어 전 응답 $(-10.36 \mathrm{~dB})$ 대비 제어 후 응답(-14.82 dB)을 보였으 며 $4.46 \mathrm{~dB}$ 의 진동레벨을 저감할 수 있었다. 반면 $4851 \mathrm{~Hz}$ 에서는 제어 전 응답 $(-17.78 \mathrm{~dB})$ 대비 제어 후 응답 $(-11.92 \mathrm{~dB})$ 을 보였으며 진동레벨이 $5.86 \mathrm{~dB}$ 증가하는 것을 보여주었다. 이것은 Fig. 6 에 언급한 Nyquist 선도에서 $(-1, j 0)$ 을 중심으로 하는 단위원 내부에 존재하는 응답 때문에 나타나는 현상이다. 
하지만 제어 후 지배적인 진동응답레벨을 나타내는 1,2 차 모드에 비교하여 $4851 \mathrm{~Hz}$ 의 응답이 $6 \mathrm{~dB}$ 이 상 작게 나타났다.

Fig. 8은 제어 전 대비 제어 후의 평판의 총운동 에너지를 나타낸 것이다. 센서가 설치된 위치의 응 답만으로는 평판 전체의 진동레벨의 변화를 평가하 기 힘들다. 따라서 한 개의 $\mathrm{FVF}$ 제어기를 통해 작 동되는 단일 $\mathrm{PZT}$ 액추에이터의 제어력이 평판 전 체의 미치는 영향을 TKE로 평가한다. Fig. 7과 유 사하게 1,2 차 모드를 포함한 저차 모드의 TKE가 크게 평가되었다. 1 차 모드의 경우 제어 전(-5.79 $\mathrm{dB})$ 대비 제어 후 $(-8.16 \mathrm{~dB})$ 를 보였으며 $2.37 \mathrm{~dB}$ 의 $\mathrm{TKE}$ 를 저감시켰다. 또한 2차 모드의 경우 제어 전 $(-13.72 \mathrm{~dB})$ 대비 제어 후(-18.66 dB)를 보였으며 $4.94 \mathrm{~dB}$ 의 진동레벨을 저감시켰다.

그리고 제어 후 $4851 \mathrm{~Hz}$ 에서 나타난 센서위치에 서의 진동레벨 증가는 $\mathrm{TKE}$ 에서 $-39.91 \mathrm{~dB}$ 를 나타 냈으며 1,2 차 모드에 비하여 $25 \mathrm{~dB}$ 이상 차이 나 므로 해당 주파수의 응답 증가는 허용 가능하다.

\section{5. 결 론}

이 연구에서는 $\mathrm{FVF}$ (filtered velocity feedback) 제어기법을 적용하여 사면이 고정된 평판의 능동진 동제어를 연구하였다. 제어액추에이터는 사각형 PZT 를 이용하였고 센서는 엑추에이터 중앙점 위치에서 평판의 속도를 측정하였다. $\mathrm{DVFB}$ (direct velocity feedback) 제어기의 안정성 및 성능 대비 개선을 목 적으로 $\mathrm{FVF}$ 제어기의 안정성 및 성능을 해석하여 다음과 같은 결론을 얻었다.

(1) FVF 제어기는 불안정성을 내포하고 있는 고 주파 대역의 응답을 줄여 안정성 향상에 효과를 보 였다. 동일한 평판 구조물에 대한 DVFB 제어기를 적용한 경우 게인 마진이 4정도로 낮았으나 $\mathrm{FVF}$ 제어기를 적용한 경우 게인마진은 약 32 정도로 8 배 향상되었다.

(2) FVF 제어기는 튜닝주파수에서 차단효과가 시작되는 저역통과필터 역할을 한다. 그러나 튜닝주 파수에서 제어기의 공진특성을 보이므로 이를 완화 하는 방법으로 제어기의 감쇠비를 조절하였다. 감쇠 비는 공진효과가 거의 사라지는 임계감쇠에 도달하 도록 설계하는 것이 필요한 것으로 판단된다. 그러
나 감쇠비를 증가함에 따라 더 넓은 주파수에서 제 어기의 위상특성이 왜곡되는 것을 보였으므로 설계 시 수용 가능한 범위에서 감쇠비를 정해야 함을 알 수 있었다.

(3) 제어성능을 예측하기 위해 게인마진 범위에 있는 한 게인 값에 대하여 성능해석을 수행하였다. 최대 게인 마진의 범위에서 증가시키면 안정한 주 파수 대역에서는 그 성능이 증가하나 불안정한 주 파수 영역의 응답은 증가하게 된다. 이를 감안하여 되먹임 속도 센서의 응답 기준으로 저주파대역 최 대 응답보다 $10 \mathrm{~dB}$ 이상 차이를 보이는 게인 값을 선택하였다. 이때 튜닝주파수 이하에선 전체 모드가 감소하는 특성을 보였고 값의 범위는 $2 \sim 5 \mathrm{~dB}$ 였다. 고주파 대역에서는 최대 $5 \mathrm{~dB}$ 이상 증가하는 특성을 보였다.

\section{참 고 문 헌}

(1) Mixson, J. S. and Powell, C. A., 1984, Review of Recent Research on Interior Noise of Propeller Aircraft, AIAA/NASA 9th Aeroacoustics Conference.

(2) Griffin, M. J., 1990, Handbook of Human Vibration, Elsevier Academic Press, London.

(3) Shin, C. J., Hong, C. S. and Jeong, W. B., 2008, Active Vibration Control of Cantilever Beams Using PZT Actuators, Transactions of the Korean Society for Noise and Vibration Engineering, Vol. 18, No. 12, pp. 1293 1300.

(4) Reza Moheimani, S. O., Halim, D. and Feming, A. J., 2003, Spatial Control of Vibration Theory and Experiments, World Scientific.

(5) Preumont, A., 1997, Vibration Control of Active Structures, Kluwer Academic Publishers.

(6) Cannon Jr., R. H. and Rosenthal, D. E., 1984, Experiments on Control of Flexible Structure with Noncolocated Sensors and Actuators, Journal of Guidance, Control and Dynamics, Vol. 7, pp. 546 553.

(7) Zhang, Q., Shelley, S. and Allemang, R. J., 1991, Active Damping Design of Flexible Structures Based on SISO and SIMO Noncollocated 
Sensor/Actuator Velocity Feedback, Journal of : A Virtual Passive Approach, Journal of Guidance, Dynamic Systems Measurement and Control - Control and Dynamics, Vol. 15, No. 5, pp. Transactions of the ASME, Vol. 113, Issue 2, pp. 259 266.

(8) Gatti, G., Brennan, M. J. and Gardonio, P., 2007, Active Damping of a Beam Using a Physically Collocated Accelerometer and Piezo Electric Patch Actuator, Journal of Sound and Vibration, Vol 303, Issues 3 5, pp. 798 813.

(9) Fanson, J. L. and Caughey, T. K., 1987, Positive Position Feedback Control for Large Space Strutures, Proceedings of the 28th Structural Dynamics Conference, Monterey, CA, pp. 588 598.

(10) Kwak, M. K., Han, S. B. and Heo, S., 2004, The Stability Conditions, Performance and Design Methodology for the Positive Position Feedback Controller, Transactions of the Korean Society for Noise and Vibration Engineering, Vol. 14, No. 3, pp. 208 213.

(11) Kwak, M. K. and Heo, S., 2007, Active Vibration Control of Smart Grid Structure by Multiinput and Multioutput Positive Position Feedback Controller, Journal of Sound and Vibration, Vol. 304, Issue 1 2, pp. 230 245.

(12) Juang, J. N and Phan, M., 1992, Robust Controller Design for Second-order Dynamic Systems 1192 1198.

(13) Kotnic, P. T., Yurkovich, S., et al., 1988, Acceleration Feedback for Control of a Flexible Manipulator Arm, Journal of Robotic Systems, Vol. 3, pp. 181 195.

(14) Preumont, A. and Loix, N., 1994, Active Damping of a Stiff Beam-like Structure with Acceleration Feedback, Experimental Mechanics, Vol. 34 , No. 1, pp. 23 26.

(15) Shin, C. J., Hong, C. S. and Jeong, W. B., 2010, Active Control of Clamped Beams using Acceleration Feedback Controllers, Transactions of the Korean Society for Noise and Vibration Engineering, Vol. 20, No. 12, pp. 1190 1199.

(16) Shin, C. J., Hong, C. S. and Jeong, W. B., 2011, Active Control of Clamped Beams using Filtered Velocity Feedback Controllers, Transactions of the Korean Society for Noise and Vibration Engineering, Vol. 21, No. 5, pp. 447 454.

(17) Meirovitch, L., 1967, Analysis Methods in Vibration, The Macmillan Company.

(18) Warburton, G. B., 1951, The Vibration of Rectangular Plates, Proceeding of Institute of Mechanical Engineering, Vol. 168, pp. 371 384. 